Galit Magrafta

Higher Studies of Israel

\title{
A PROFESSIONAL LEARNING COMMUNITY AS A FACTOR OF THE PROFESSIONAL DEVELOPMENT OF TEACHERS
}

Aвstract. Magrafta Galit, A Professional Learning Community as a Factor of the Professional Development of Teachers [Profesjonalna społeczność ucząca się jako kontekst rozwoju zawodowego nauczycieli]. Studia Edukacyjne nr 44, 2017, Poznań 2017, pp. 417-426. Adam Mickiewicz University Press. ISSN 1233-6688. DOI: $10.14746 /$ se.2017.44.26

The article presents the importance of the professional learning community in the school framework. It discusses the creation of a learning community, its characteristics, advantages, and the challenges in the leadership and establishment of a professional learning community. In addition, the article presents the importance of the introduction of a learning community into educational frameworks and provides a solution to the resources that pertain to the time or systemic flexibility. This article highlights the importance of collaborations, peer learning, and a productive discourse among teacher colleagues.

Key words: professional learning community, professional development

Tell me and I forget. Teach me and I remember. Share with me and I learn.

Benjamin Franklin

\section{Introduction}

Researchers of education and shapers of policy in the field of teaching see a need to improve the quality of teaching and to provide opportunities for professional development for teachers, with the aim of facilitating the increased depth of the knowledge and improving the teachers' pedagogical skills. ${ }^{1}$

${ }^{1}$ H. Borko, Professional Development and Teacher Learning: Mapping the Terrain, Educational Researcher, 2004, 33(8), p. 3-15. 
Consequently, there was increased recognition of the need to integrate the theoretical knowledge about teaching in the different fields of knowledge and the cumulative practical experience of the teachers who work in this in their professional lives. ${ }^{2}$

The concept of 'professional learning community' developed to help the teachers adjust to a dynamic reality. A professional learning community is in essence a group of educators who work in cooperation so as to improve the achievements of all the leaners in the school. ${ }^{3}$

The professional learning community is based on constructivist learning theories, which perceive the learner as an interpreter, who is involved in the building of information about the world and who has the ability to implement judgment and reflection on his ideas and to evaluate them and to correct them as needed. ${ }^{4}$

In the process of a professional learning community there are discussions that help the teachers highlight their professional vision that is defined in the ability to identify the main characteristics of the interactions in the class and to understand and interpret them. ${ }^{5}$

The importance of this article is to create awareness in the building of professional learning communities in the educational frameworks so as to examine together their knowledge and practices so as to improve professionally.

\section{What Are Professional Learning Communities?}

The schools that operate as a professional learning community develop processes, strategies, and structures for cooperative learning, through adjustment to dynamism and changes in the situations that occur in uncertainty. ${ }^{6}$

Accordingly, a professional community has the starting point of the adjustment of the process to the learner and performs a process of information processing that improves the organization's potential abilities, through its adjustment to the needs of the environment. This learning process as a pro-

${ }^{2}$ V. Farnsworth, I. Kleanthous, E. Wenger-Trayner, Communities of Practice as a Social Theory of Learning: a Conversation with Etienne Wenger, British Journal of Educational Studies, 2016.

${ }^{3}$ D. Williams, Urban Education and Professional Learning Communities, The Delta Kappan Gamma Bulletin, 2013, p. 31-39.

${ }^{4}$ M. Birenbaum, Assessment for Learning and Characteristics of a School Professional Community and Class Culture that Empowers It, [in:] Assessment, Jewish Education, and the History of Education: A Collection in the Memory of Professor Aryeh Levy, Ed. Y. Keshti, Tel Aviv University, the School of Education and, Tel Aviv 2009, p. 77-100.

${ }^{5}$ H. Borko, J. Jacobs, K. Koellner, Contemporary Approaches to Teacher Professional Development, [in:] International Encyclopedia of Education, Eds. P. Peterson, E. Baker, B. McGaw, Oxford 2010, 7, p. 548-556.

${ }^{6}$ W. Admiraal, D. Lockhorst, J. van der Pol, An Expert Study of a Descriptive Model of Teacher Communities, Learning Environment Research, 2012, 15, p. 345-361. 
fessional learning community is characterized by clear goals and a pan-organizational learning strategy, which encourage openness, trust, initiative, and experience. $^{7}$

A professional learning community is a group of professionals who examine together their knowledge and practices and discuss them, so as to improve in professional terms. ${ }^{8}$ Teachers in a professional learning community meet regularly, research the relationship between the practice and the learning products of their students, analyze the processes of teaching and learning, draw conclusions, and perform changes so as to improve their teaching and the learning of their students. ${ }^{9}$

The assumption that guides the activity of the heterogeneous as a community of learners is that each one of its members has unique knowledge and unique insights that can contribute to others and that without these contributions from others the individual will learn less. The equal relations between experts on different levels and from different fields are the ideological foundation stones of the community of learners: a variety of information sources and viewpoints enriches them all, including the most skilled and senior experts.

Learning in the community may increase the intellectual power of the collective. The participants in the community are forged into a team of shared thinking, planning, and activity.

Kiney (2006) defines a 'community of learners' as a community whose participants are different from one another. It is autonomous and has self-organization. The members of the community are responsible for their functioning in the process of the acquisition of the knowledge and the production as a product. The person is an involved participant in the processes that occur in the community of learners and in addition the person is a reflective observer who is aware of his activity and who thinks about it. The knowledge that is accumulated is shared by all the common members. The learning in the 'community of learners' is perceived as a process of interactive building, in which the learners, both older and younger, create new insights, through a constant dialogue with themselves and with others. A learning community offers its members support in the process of their coping with challenges and with changes in their close work environment and transforms their learning into 'lifelong learning' in actuality.

${ }^{7}$ E. Khoo, B. Cowie, Analysing an Online Learning Community from Personal, Interpersonal and Community Planes of Development, [in:] Proceedings of Global Learn Asia Pacific 2010, Eds. Z. Abbas et al. (p. 4222-4231), AACE. Retrieved from http://www.editlib.org/p/34523.

${ }^{8}$ M. Birenbaum, Assessment for Learning and Characteristics of a School Professional Community, p. 77-100.

${ }_{9}$ A. Balenga, G. Landler-Perdo, M. Shachar, Learning Communities of Teachers: An Invited Review as Background Material for the Work of the Language and Literacy Committee, Initiative of Applied Research in Education, The Israeli National Academy of the Sciences, 2011, http:// education.academy.ac.il. 


\section{Characteristics of Professional Learning Communities}

The objective of the learning community is to promote the collective knowledge of all the members in the community, with the support of the growth of the personal knowledge of all the members. They become partners in the community of learners in which every person has the responsibility for the promotion of the learning.

The research literature indicates main characteristics of professional learning communities.

\section{Reflective Dialogue}

Effective professional learning of teachers includes components of reflection on practice, investigation of ways of teaching, and constant self-examination. The expertise of the teachers is characterized by the ability to conceptualize the teaching work and to examine the practice of critical examination. These reflective abilities develop from the in-depth observation of the practice of the teaching and the learning that it enables. ${ }^{10}$

\section{Research of Practice - Feedback}

The professional learning processes of teachers who focus on the relationships between specific teaching practices and the students' learning and achievements improve the students' learning and achievements. In every pedagogical discourse of teachers, the focus needs to be the students' learning and the relationship between the teachers' teaching and the students' learning. It is important that the teachers look at their work, analyze the actual performances of themselves and their students, and engage in continuous feedback, so as to develop and implement more effective teaching methods, think about new practices in their specific context, and share the knowledge and personal experience. ${ }^{11}$

\section{Relations of Trust and Norms of Sharing}

Cooperation is a key trait of an effective professional learning community. A professional learning community where there is high trust and reciprocal and professional respect produces a safe space that enables the teacher to learn and develop professionally. It serves as an emotional and professional 'safety network' in experiences that are not successful.

${ }^{10}$ E.E.J. Thoonen et al., Building School-Wide Capacity for Improvement: The Role of Leadership, School Organizational Conditions, and Teacher Factors, School Effectiveness and School Improvement, 2012, 23, p. 441-460.

${ }^{11}$ C. Lomos, R. Hofman, R. Bosker, Professional Communities and Student Achievement: A Meta-Analysis, School Effectiveness and School Improvement, 2011, 22, p. 121-148. 
There is significant cooperation when the teachers develop skills of listening, respect the different attitudes, build reciprocal trust, cultivate the others, and serve as a personal example with integrity. In professional communities the teachers reveal their ways of teaching and cope with different opinions and share together what traditionally is perceived as personal (Stanley, 2011). ${ }^{12}$

\section{Data-Based Learning and Assessment}

Professional processes of learning of teachers are optimal processes when they are based on a variety of data of different types and when there is assessment that examines the results in the comparison to the objectives.

The shared goal addresses the teachers' learning in agreement with the operative actions in the school. The data serve as a source for the examination of the teaching for the construction of a culture of assessment-learning as a basis for reflection that the teachers hold in a professional learning community. The evaluation data provide a basis both for the setting of objectives before the entry into the process of the improvement of the learning and the teaching and during the process itself - to obtain a picture of the situation that indicates to the staff if it is on the right way and if the objectives are being fulfilled and what needs to be changed on the way. ${ }^{13}$

\section{Reciprocal Commitment of Teachers to their Students' Success}

Learning communities that put at the center of the analysis the work of the student and information on the student provide opportunities for teachers to develop a shared understanding of common mistakes and teaching strategies. The power of the focus on the student's data and a professional dialogue is expressed in the consistent success of the students' achievements in the elementary schools. Analysis of the students' work deepens the teachers' content knowledge and the knowledge how to teach it to the students. It helps the teachers understand how students learn specific content, provides active opportunities for practical learning, and helps the teachers acquire new knowledge and implement it, from the teachers' commitment to their students' success. ${ }^{14}$

${ }^{12}$ J. Nehring, G. Fitzsimons, The Professional Learning Community as Subversive Activity: Countering the Culture of Conventional Schooling, Professional Development in Education, 2011, 37(4), p. 513-535.

${ }^{13}$ S. Leahy, D. William, From Teachers to Schools: Scaling Up Professional Development for Formative Assessment, [in:] Assessment and learning (2nd edition), Ed. J. Gardner, Thousand Oaks, CA 2012.

${ }^{14}$ O. Bar-Yaakov, D. Tubin, The Evolution of Success, [in:] Leading Schools Successfully - Stories from the Field, Eds. C. Day, D. Gurr, London, UK 2014, p. 19-30. 


\section{Structured Processes and Regular Mechanisms for Teamwork}

The setting of the teamwork is the basis for the creation of permanence and stability, without which significant professional learning is not possible. The setting gives stability and security and conveys seriousness and commitment. Such a setting includes the construction of the frequency and length of the sessions, annual planning, and planning of each and every session. Consistency and stability constitute the platform that enables significant learning. ${ }^{15}$

\section{Contribution of the Professional Learning Community in the School}

Learning communities contribute to the constant improvement of knowledge and professional skills of teachers and to their feeling of efficacy to bring their students to achievements. The teachers' sense of efficacy increases when the professional learning and planning are undertaken together in teams. These two variables - knowledge and professional skills and sense of efficacy - are directly related to the students' achievements. ${ }^{16}$

In the meetings of the teams of teachers, their ways of teaching are examined and their influence on the students' learning. Defined goals are set for the teachers' teaching and for the students' learning and achievements. The teachers strive to achieve the goals and evaluate the degree to which they are achieved regularly.

In addition, the teachers share with one another what is done in their classes and even hold peer observations and reflection on them. They plan together lessons, tasks, and tests, and they discuss together the students' works, the students' specific difficulties, and ways of coping with these difficulties in teaching.

A culture of collective responsibility for all the students develops - not as a slogan but as but as a real intention. ${ }^{17}$

Teachers who are involved in cooperative learning with colleagues for the most part indicate about themselves that they can change or modify their teaching methods as a means for the improvement of the learner's learning and success. In addition, professional interactions create cooperative collecti-

${ }^{15}$ C. Schechter, Learning from Success as Leverage for a Professional Learning Community: Exploring an Alternative Perspective of School Improvement Process, Teachers College Record, 2010, 112,1 , p. 182-224.

${ }^{16}$ A. Balenga, G. Landler-Perdo, M. Shachar, Learning Communities of Teachers.

${ }^{17}$ R. DuFour, What Is a "Professional Learning Community"? Educational Leadership, 2004, 61(8), May, p. 6-11; H. Timperley, Teacher Professional Learning and Development, Educational Practices Series, 18, International Academy of Education and International Bureau of Education, Brussels 2008. 
ve memory, which is unique and more developed than individual memory, since they incorporate activities, processes, and methods of the organization's members.

Cooperative learning is a part of the professional learning culture. Thus the learning needs to be based on critical social life undertaken in a constant dialogue. Therefore, all the participants are partners and responsible for the actions of the collective, and the dialogue is both the means and the end and all the participants express emotions, attitudes, and meanings in a way of speaking. ${ }^{18}$

The recognition of the importance of the professional learning community derives also from contemporary pedagogical perceptions that describe the learning as a process that occurs in social-cultural contexts. According to these perceptions, learning exists in the interaction among people, from the close relationship between learning and practice and from sharing in the practice in the professional community. The social-cultural perception of the learning suits also the class of children and the staffs of teachers. ${ }^{19}$

In the learning community there is an active and dynamic process of learning and reciprocal productivity with personal and group reflection, and at the end new knowledge is created. The goal of the community is to assimilate the knowledge and adjust it to the members of the community after the identification of their needs and abilities. The learners in the professional learning community are exposed in the school environment to a consistent model of 'lifelong learning'. They see personal examples of adults who search for learning opportunities and enjoy the achievement of new information. In addition, a learning community offers its members support in light of new challenges. ${ }^{20}$

\section{Difficulties of Professional Learning Communities}

The main difficulties in the building of the professional learning community are the problem of time and the inculcation of practices, ${ }^{21}$ since the learning process in the professional learning community requires time. Time is required so that the members in the community will know one another, will trust one another, and will believe in one another.

${ }^{18}$ J. Sebastian, E. Allensworth, The Influence of Principal Leadership on Classroom Instruction and Student Learning: A Study of Mediated Pathways to Learning, Educational Administration Quarterly, 2012, 48, p. 626-663.

${ }^{19}$ T. Yechieli, How to Have Constructivist Learning, Echo of Education, 2008, 82(4), p. 40-44.

${ }^{20}$ E. Mushayikwa, F. Lubben, Self-Directed Professional Development - Hope for Teachers Working In Deprived Environments, Teaching and Teacher Education, 2009, 25, p. 375-382.

${ }^{21}$ L.S. Shulman, Learning Communities and Communities of Teachers, Jerusalem 1996. 
Aubussion, Frances, and Brady (2007) indicate a problem in the willingness of some of the teachers to participate in the community and the difficulty in meeting the schedule that brings them to feel that they are found with a lack of time that makes it difficult for them to focus on the teaching tasks.

De Jong (2012) notes that learning communities will not function optimally in an organizational culture that does not support the critical examination of the teaching practices. Time is a critical factor, and many teachers are concerned that the time at their disposal to integrate and assimilate the innovations they learned in the communities is limited.

Sjoer and Meirink (2016) indicate differences in the styles of thinking and learning of the teachers as a factor that makes the learning in the community difficult. Teachers are different from one another in needs, ideas, and experiences. Such differences and others make it difficult for the teachers to cooperate in the building of the curriculum.

In addition, many teachers have encountered the difficult to express open criticism of their colleagues' work and have called the weak criticism 'safe talk'. The cooperation misses its goal if teachers rely only on the encouragement and are not involved in critical dialogue of their peers' activity, which is called 'sharing'. ${ }^{22}$

It is possible to indicate difficulties related to the change in the work of the teacher, who is accustomed to work alone. Despite the view that work in cooperation will yield better trust, it is still possible to find in many schools the isolation of teachers. ${ }^{23}$

\section{Conclusion}

The article examines the implications of a model of professional development based on a professional learning community of teachers and integrating theory and practice as a tool for the professional development of teachers in the 21st century.

The dynamic pace of life requires the school to adjust to a rapidly changing reality. The teachers need to evince awareness of the environment, update with the many innovations, and cope with standardization, multiculturalism, globalization, and the knowledge era. ${ }^{24}$

${ }^{22}$ O. De Jong, Empowering Teachers for Innovations: The Case of Online Teacher Learning Communities, Creative Education, 2012, 3, Supplement, p. 125-129.

${ }^{23}$ R. DuFour, What Is a "Professional Learning Community"? p. 6-11.

${ }^{24}$ H. Kurland, H. Peretz, R. Hertz-Lazarowitz, Leadership Style and Organizational Learning: The Mediate Effect of School Vision, Journal of Educational Administration, 2010, 48(1), p. 7-31. 
A professional learning community can effect a change and lead to successes, both of the teachers and of their students. A continuous learning process requires the teachers to look at the good of all and enlist for the desired change, or in other words, to enable the introduction of changes, to open up without fear for reflection and peer learning, to be a part of a thinking team and to experience satisfaction, enjoyment, and success from their work.

It is very important that the educational system enable opportunities for the creation of professional communities and provide opportunities for existing communities to remain over time. A school that wants to act as a professional learning community needs to meticulously plan the entire process and act from true desire, to change, and to succeed. ${ }^{25}$

Schools that have professional learning communities indicate the improvement of achievements, great loyalty, and strong desire of the staff members to succeed.

\section{BIBLIOGRAPHY}

Admiraal W., Lockhorst D., van der Pol J., An Expert Study of a Descriptive Model of Teacher Communities, Learning Environment Research, 2012, 15.

Aubusson P.S., Frances D.S., Brady L., Action Learning in Teacher Learning Community Formation: Informative or Transformative? Teacher Development, 2007, 11(2).

Balenga A., Landler-Perdo G., Shachar M., Learning Communities of Teachers: An Invited Review as Background Material for the Work of the Language and Literacy Committee, Initiative of Applied Research in Education, The Israeli National Academy of the Sciences, 2011, http:/ / education.academy.ac.il (Hebrew).

Bar-Yaakov O., Tubin D., The Evolution of Success, [in:] Leading Schools Successfully - Stories from the Field, Eds. C. Day, D. Gurr, Routledge, London, UK 2014.

Birenbaum M., Assessment for Learning and Characteristics of a School Professional Community and Class Culture that Empowers It, [in:] Assessment, Jewish Education, and the History of Education: A Collection in the Memory of Professor Aryeh Levy, Ed. Y. Keshti, Tel Aviv University, the School of Education and Ramot Press, Tel Aviv 2009.

Borko H., Professional Development and Teacher Learning: Mapping the Terrain, Educational Researcher, 2004, 33(8).

Borko H., Jacobs J., Koellner K., Contemporary Approaches to Teacher Professional Development, [in:] International Encyclopedia of Education, Eds. P. Peterson, E. Baker, B. McGaw, Oxford 2010, 7.

De Jong O., Empowering Teachers for Innovations: The Case of Online Teacher Learning Communities, Creative Education, 2012, 3, Supplement.

DuFour R., What Is a "Professional Learning Community"? Educational Leadership, May 2004, 61(8) .

Farnsworth V., Kleanthous I., Wenger-Trayner E., Communities of Practice as a Social Theory of Learning: a Conversation with Etienne Wenger, British Journal of Educational Studies, 2016.

\footnotetext{
${ }^{25}$ R. DuFour, What Is a "Professional Learning Community"? p. 6-11.
} 
Kaney S., Ecological Thinking - A New Approach to Educational Change, Klil and Mofet Institute, Tel Aviv 2006 (Hebrew).

Khoo E., Cowie B., Analysing an Online Learning Community from Personal, Interpersonal and Community Planes of Development, [in:] Proceedings of Global Learn Asia Pacific 2010, Eds. Z. Abbas et al. (p. 4222-4231), AACE. Retrieved from http:// www.editlib.org/p/34523

Kurland H., Peretz H., Hertz-Lazarowitz R., Leadership Style and Organizational Learning: The Mediate Effect of School Vision, Journal of Educational Administration, 2010, 48(1).

Leahy S., William D., From Teachers to Schools: Scaling Up Professional Development for Formative Assessment, [in:] Assessment and learning (2nd edition), Ed. J. Gardner, Sage, Thousand Oaks, CA 2012.

Lomos C., Hofman R., Bosker R., Professional Communities and Student Achievement: A Meta-Analysis, School Effectiveness and School Improvement, 2011, 22.

Mushayikwa E., Lubben F., Self-Directed Professional Development - Hope for Teachers Working In Deprived Environments, Teaching and Teacher Education, 2009, 25.

Nehring J., Fitzsimons G., The Professional Learning Community as Subversive Activity: Countering the Culture of Conventional Schooling, Professional Development in Education, 2011, 37(4).

Schechter C., Learning from Success as Leverage for a Professional Learning Community: Exploring an Alternative Perspective of School Improvement Process, Teachers College Record, 2010, 112, 1 .

Sebastian J., Allensworth E., The Influence of Principal Leadership on Classroom Instruction and Student Learning: A Study of Mediated Pathways to Learning, Educational Administration Quarterly, 2012, 48.

Shulman L.S., Learning Communities and Communities of Teachers, Mandel Institute, Jerusalem 1996 (Hebrew).

Sjoer E., Meirink J., Understanding the Complexity of Teacher Interaction in a Teacher Professional Learning Community, European Journal of Teacher Education, 2016, 39(1).

Thoonen E.E.J., Sleegers P.J.C., Oort F.J., Peetsma T.T.D., Building School-Wide Capacity for Improvement: The Role of Leadership, School Organizational Conditions, and Teacher Factors, School Effectiveness and School Improvement, 2012, 23.

Timperley H., Teacher Professional Learning and Development, Educational Practices Series, 18, International Academy of Education and International Bureau of Education, Brussels 2008.

Williams D., Urban Education and Professional Learning Communities, The Delta Kappan Gamma Bulletin, 2013.

Yechieli T., How to Have Constructivist Learning, Echo of Education, 2008, 82(4), (Hebrew). 